\title{
Hepatitis E in Pregnant Women and the Potential Use of HEV Vaccine to Prevent Maternal Infection and Mortality
}

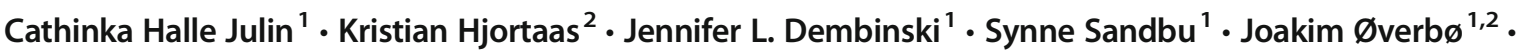 \\ Kathrine Stene-Johansen ${ }^{1} \cdot$ Susanne Dudman ${ }^{1,2}$
}

Published online: 20 November 2019

(C) Springer Nature Switzerland AG 2019

\begin{abstract}
Purpose of Review Hepatitis E (HEV) is a continuing public health problem in developing countries, causing high mortality in pregnant women. This article reviews the latest knowledge on HEV in pregnancy, the vaccine candidates that have reached clinical trials, and their potential use during pregnancy.

Recent Findings New evidence suggests that a genotype-specific tropism to uteroplacental cells contributes to the multifactorial pathology leading to the increased severity of HEV during pregnancy. Data from pregnant women inadvertently vaccinated are limited but show similar rates of adverse events as non-pregnant women, and no evident harm to newborns. Protective anti-HEV IgG antibodies are estimated to last longer after vaccination than natural infection. Accelerated vaccination appears safe and provides protective antibodies similar to a normal dosing regimen.

Summary HEV239 is the most extensively studied vaccine and has been shown to be safe and effective, but more data are needed to recommend use of this vaccine on a global basis. Further studies should focus on safety and efficacy in pregnant women, and evaluate a shorter two-dose regime, which is highly warranted in outbreak situations.
\end{abstract}

Keywords Hepatitis E virus · HEV · Pregnancy · Mortality · Hepatitis E vaccine · Vaccination · Pregnancy · Maternal death · Maternal immunization $\cdot$ Vertical infection $\cdot$ Liver disease

\section{Introduction}

Hepatitis E virus (HEV), the causative agent of hepatitis E infection, circulates globally and at especially high rates in developing countries, such as areas in Africa and Asia where drinking water may frequently be contaminated. Approximately 2 billion persons live in areas that are endemic for HEV, and the World Health Organization (WHO)

This article is part of the Topical Collection on Vaccines in Pregnant Women and Infants

Cathinka Halle Julin

cathinkahalle.julin@fhi.no

Susanne Dudman

susannmg@medisin.uio.no

1 Division of Infection Control and Environmental Health, Norwegian Institute of Public Health (NIPH), Folkehelseinstituttet, Postboks 222 Skøyen, 0213 Oslo, Norway

2 University of Oslo, Institute of Clinical Medicine, Oslo, Norway estimates that more than 20 million infections occur worldwide annually, leading to 44,000 deaths [1]. The highest mortality rate among persons infected with HEV has been recorded in pregnant women, with approximately $25 \%$ of acute cases occurring in the third trimester having a fatal outcome.

The virus, discovered in 1983 by Balayan and co-workers, is non-enveloped and has a single-stranded RNA genome of approximately 7200 bases [2]. The HEV genome contains three open reading frames (ORFs) coding for the nonstructural proteins (ORF1), the capsid protein (ORF2), and a phosphoprotein (ORF3) functioning to facilitate viral release from the host cell.

$\mathrm{HEV}$ is a member of the genus Orthohepevirus belonging to the Hepeviridae family, and so far eight genotypes have been characterized [3]. Among these, genotypes 1 and 2 are restricted to human disease, and commonly cause large outbreaks in developing countries, although some cases in industrialized countries are related to recent travel to endemic areas. Huge epidemics of hepatitis E genotype 1 have occurred in South Asia for decades, mainly affecting individuals between 
the ages of 15 and 40 years [4]. Poor sanitation and lack of safe water supply pose special challenges in conflict situations and refugee camps. Genotypes 3 and 4 infect both humans and a wide range of animals and have mainly caused sporadic cases in industrialized areas in recent years. The remaining genotypes 5-8 are more rarely detected and have mainly been isolated from animals, although a few sporadic cases of genotype 7 have been reported in humans [5]. This review focuses on genotypes 1 and 2, which are the most common etiologic agents of severe acute hepatitis in pregnant women.

Among non-pregnant persons, hepatitis E disease is usually mild and self-limiting. Seroepidemiological studies show that antibodies to HEV can be found in all age groups worldwide, as well as in individuals with no history of hepatitis, indicating frequent asymptomatic infection [4]. However, hepatitis E infection occurring in pregnancy carries a high risk of acute liver failure (ALF), with the highest risk of fatality if it occurs in mothers during the second or third trimester [4]. The risk of $\mathrm{HEV}$ infection for the fetus is also substantial, with high fetal and neonatal mortality and morbidity rates $[6 \bullet]$.

\section{Hepatitis E Virus Pathology}

HEV is primarily a hepatotropic virus, and most of the classical symptoms are associated with liver damage. The fact that the virus is not cytotoxic, and that the clinical symptoms as well as the increases in hepatic transaminase enzymes cooccur with the rise of IgM rather than the virus load, suggests an immune-mediated liver damage. The exact mechanism of this injury is still unclear but seems to be a complex interplay involving both Th1 and Th2 immune responses, with natural killer cells, type 1 IFN signaling pathways, and cytotoxic T cells as important components $[7,8]$. In order to successfully multiply in humans, HEV has developed several methods of immune eversion such as blocking different pathways of NF-KB stimulation, leading to downregulated cellular immunity and lymphocyte apoptosis $[9,10]$.

After an incubation period ranging from 2 to 10 weeks following ingestion of the virus, liver disease develops due to the hepatotropic HEV passing through the intestinal mucosa into the blood stream and reaching the portal circulation where the virus infects hepatocytes [4]. Anti-HEV IgM is normally present $1-2$ weeks after HEV can be detected, and anti-HEV IgG antibodies appear shortly thereafter [11]. IgG increases in titer [12] and avidity [13] during the following months. Anti-HEV antibodies are directed against antigens produced by ORF2 in the viral genome. The T cell response to HEV infection is poorly understood, but both CD4+ and CD8+ cells targeting all ORFs are produced during an infection. Both cellular and humoral immunity are likely important in both eliminating an HEV infection and protecting against subsequent infections [8].
The immune system changes during pregnancy in order to protect the fetus. This may happen because pregnancy resembles the state of transplantation with a modified immune system to tolerate a fetus that is genetically different from the pregnant host. Some of the important alternations that occur, are the Th2 bias that results in a decreased cellular immunity during pregnancy [14], and the pregnancy-related increases in progesterone, estrogen, and human gonadotropin hormone that suppresses NF-KB [15]. Cytokines such as TGF- $\beta$, interleukin 4 , and interleukin 10 secreted from the placenta and trophoblast cells further inhibit cell-mediated immunity [5]. The combined alteration of the immune response by both virus and pregnancy is likely an important factor in the increased severity of HEV during pregnancy and is summarized in Fig. 1.

High levels of pregnancy-related hormones might also contribute to a more severe infection through a direct stimulating effect on HEV proliferation [16]. The levels of both estrogen and its receptor ESR $2 \beta$ are correlated with maternal mortality in HEV infection during pregnancy [17].

Once inside the body, the virus can exist in a partially enveloped stage without visible antigens, thereby hiding its presence from opsonizing antibodies. Infected cells also shed a large number of modulated ORF2 particles to further hamper antibody-induced neutralization of the virus [18]. This might be especially problematic in pregnant women who have a reduced cellular defense and thereby fewer alternatives to stop the virus.

HEV-1 was recently found to replicate more easily and to elicit a stronger response than HEV-3 in decidual and placental tissues $[19 \cdot, 20]$. This can result in tissue alterations and injuries that could cause dysfunction in the fetal-maternal interface, resulting in vertical HEV transmission in utero and increased systemic inflammation [19•]. Moreover, HEV-1 contains an extra open reading frame (ORF4) compared with HEV-3, that is translated upon endoplasmic reticulum stress [21] and could play a role in the genotype variation.

Several environmental factors might render pregnant women in low-income countries more susceptible to serious HEV infections. Nutritional deficiencies such as lack of folic acid and vitamin $\mathrm{D}$, together with a high infectious disease burden, can cause an immune dysregulation that increases the risk of clinically significant HEV disease [5, 22]. A deficiency of vitamins might also make it difficult for the mother's system to handle oxidative stress associated with both pregnancy and HEV infection [23].

\section{Clinical Manifestations of Hepatitis E}

Globally, hepatitis $\mathrm{E}$ virus is one of the most frequent causes of acute hepatitis [1]. Acute hepatitis E is generally self-limiting, but can lead to fulminant hepatitis, ALF, and death. The symptoms may be absent, non-specific, or follow a clinical course similar to other causes of acute hepatitis [5]. A large 
Fig. 1 Proposed mechanisms of HEV pathology in pregnant women infected with genotype 1 . The figure shows how both the virus and pregnancy modulate the immune response, resulting in an increased risk of liver failure and maternal complications

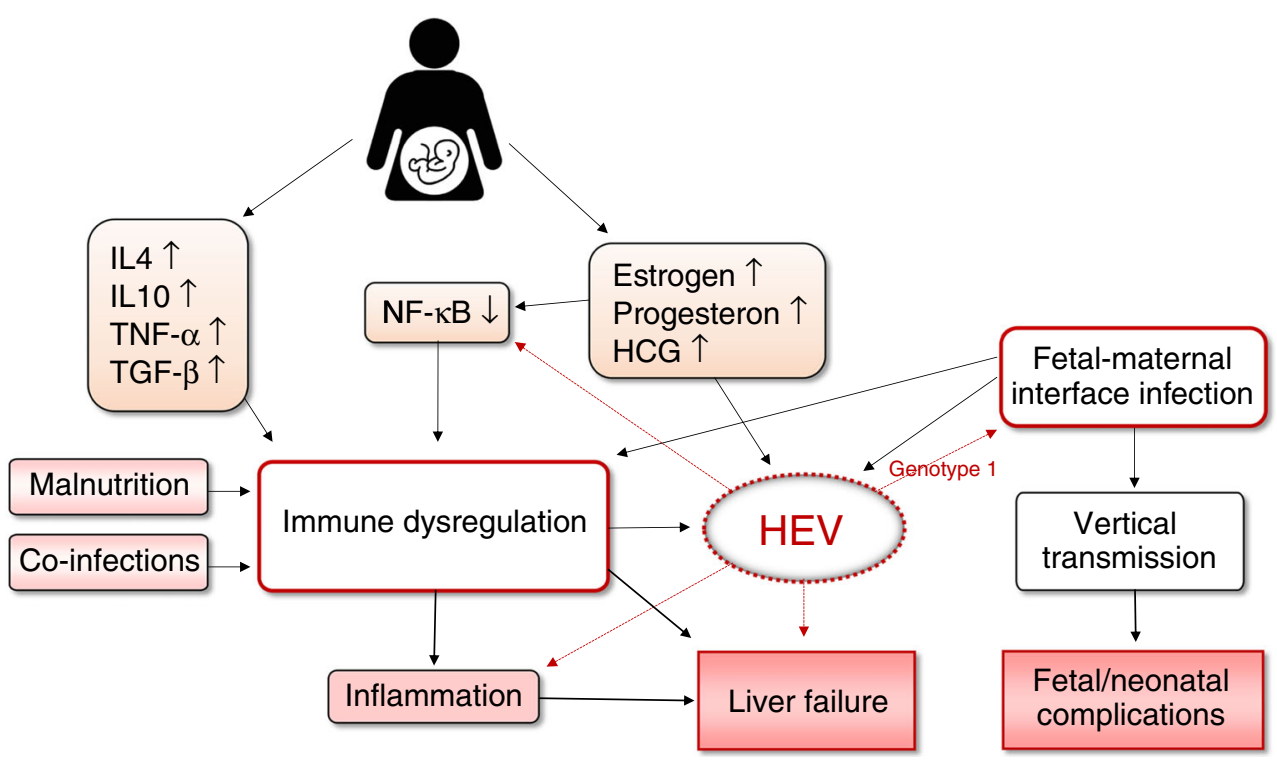

proportion of those infected with HEV develop only a mild liver injury with anicteric hepatitis and with few or no symptoms [4]. Typically, in a symptomatic course of infection, the symptoms last from 1 to 6 weeks. The initial phase is characterized with mild fever, reduced appetite, nausea, and vomiting. Other typical signs are jaundice with pale stool and dark urine and a tender, slightly enlarged liver [24].

Signs of ALF may include reduced synthesis of proteins from the liver and coagulation disorders, hepatic encephalopathy, cerebral edema, and other neurological complications [4]. Acute hepatitis $\mathrm{E}$ infection caused by genotype 1 or 2 rarely $(<1 \%)$ progress to ALF [4]. ALF is also rare among patients infected with genotypes 3 and 4 and occurs mostly in persons with pre-existing liver disease [25]. Chronic infection is known with genotypes 3 and 4, but close to non-existing with genotypes 1 and 2 [4]. The mortality rate of HEV in the general population is low $(0.2$ to $1 \%)$, but much higher in the pregnant population [5].

The initial phase of HEV infection does not differ in pregnant and non-pregnant women [5]. However, in pregnant women, the infection often progresses rapidly into a more severe hepatitis and ALF, particularly in women infected during the second or third trimester [6•]. Pregnant women with ALF may develop complications such as disseminated intravascular coagulation, encephalopathy, postpartum hemorrhage, and hepatic coma $[5,26]$, which can lead to maternal death and fetal loss. The newborn can also be affected, resulting in low birth weight, premature delivery, and, in between 25 and $56 \%$ of cases, stillbirth [5]. A review by Bergløv et al. from 2019 estimated the case fatality rate (CFR) to be $26 \%$ among pregnant women with confirmed HEV infection, with $33 \%$ fetal and $8 \%$ neonatal mortality $[6 \bullet]$. The maternal mortality in this review may however be an overestimate due to inclusion of only symptomatic women; better estimates could be gained from a case-control study [6•].

The higher morbidity and mortality in pregnant women suffering from HEV infection have mostly been reported from countries dominated by genotype $1[4,5]$. However, in Egypt, a country with high seroprevalence of genotype 1 , severe hepatitis $E$ in pregnant women is rarely reported and a recent study from China reported higher incidence of adverse pregnancy outcome from genotype 4 infection [27]. Further research is needed to understand this discrepancy.

\section{Transmission Routes}

The main transmission route of HEV is fecal-oral, most commonly through fecal contamination of drinking water caused by poor sanitation [1]. The virus can also be transmitted by direct contact, vertically from mother to fetus, and through blood transfusion. The vertical transmission route is of special interest because of the possible link to premature births and prenatal/neonatal mortality. The rate of vertical transmission varies between 23.3 and 50\% [28]. Further investigations are needed to fully understand the contribution of vertically transmitted HEV infection to fetal and neonatal morbidity and mortality [29].

\section{Treatment and Prevention}

In non-pregnant persons, acute HEV is mainly a self-limiting disease not requiring treatment. Ribavirin with or without interferon can be used to assist viral clearance if necessary, but is contraindicated during pregnancy [5]. In the case of HEVinduced ALF, transplantation is a possible treatment [30]; however, this treatment is not available in most high endemic 
areas. Prevention of the disease is therefore considered the most effective approach to control HEV [1].

Since many outbreaks occur in areas with poor sanitation, providing safe drinking water and improving sanitation are good strategies to limit transmission of the disease. However, these interventions are resource demanding and take time in low- and middle-income countries (LMIC), and may not be sufficient to halt outbreaks. Other more specific and effective measures are therefore needed.

A safe and effective vaccine could be used as a pre-emptive approach. Vaccination against HEV could significantly reduce morbidity, especially for vulnerable groups where the infection can be life-threatening, including pregnant women, immunosuppressed patients, or individuals with chronic liver disease in both high- and low-income countries. Vaccination could also serve to control outbreaks, since HEV outbreaks may occur over longer periods as seen in refugee camps [31].

\section{Hepatitis E Vaccine Development}

Development of a vaccine against HEV began in 1998. Due to a lack of an efficient HEV cell culture system [32], molecular approaches have been employed to develop recombinant vaccines based on the ORF2 viral capsid protein [33]. Xing et al. first demonstrated how the ORF2 peptide (pORF) could selfassemble into a virus-like particle (VLP) presenting multiple epitopes on the surface, displaying its potential as a vaccine candidate [34]. Several vaccine candidates based on pORF2 have since gone through preclinical studies, as discussed in the review by Cao et al. [33] and therefore not included in this review. However, the few candidates in clinical trials are described in more detail below.

\section{Clinical Trials of HEV Vaccines}

Only three HEV vaccine candidates have gone through clinical trials so far (Fig. 1). The first vaccine was rHEV (GlaxoSmithKline, Brentford, UK), which was a baculovirus-expressed 56-kDa protein based on the 112-607 part of ORF2 of a genotype 1 strain. After showing that this vaccine candidate could protect non-human primates against acute hepatitis after challenge with homologous and heterologous HEV genotypes [35], it proceeded to a phase I trial [36]. The trial results indicated that the vaccine was safe and immunogenic in humans, and a phase II trial was further conducted in Nepal, including 2000 healthy adults randomly assigned to three doses of rHEV or placebo [37]. Despite the promising results from this trial, which showed $95 \%$ efficacy and an acceptable safety profile, it did not progress through further clinical development partly due to limited commercial potential [38].

The second vaccine to advance through clinical trials was the HEV239 (Hecolin®; Xiamen Innovax Biotech), which is an $E$. coli-expressed recombinant protein based on the 368-606 part of ORF2 of a genotype 1 strain of HEV [39]. Animal studies showed that HEV239 was highly immunogenic in rhesus macaques, with a similar efficacy as the control vaccine rHEV [39]. A phase II trial further demonstrated HEV239 to be safe and immunogenic for humans, with $100 \%$ seroconversion after three doses of the vaccine [40]. In a large phase III trial, including more than 100,000 healthy adults in China, the vaccine was shown to be safe and highly efficacious against HEV disease $(100 \%$ after three doses of vaccine, $95 \%$ CI $72.1-100$ ). It was subsequently licensed in China in 2011 by the China's State Food and Drug Administration with the trade name Hecolin ${ }^{\circledR}$, and finally launched in 2012 [38]. Additionally, to demonstrate the ability of commercial scale manufacturing of HEV239, Zhang et al. showed that the antigen production is robust and scalable [41], and that the prefilled syringes are stable at $2-8{ }^{\circ} \mathrm{C}$ for 24 months [42].

In 2016, the WHO published their initial position paper on hepatitis $E$ vaccination, making recommendations on the use of hepatitis E vaccine in a global context. This paper focused primarily on the available evidence concerning the most promising and only hepatitis $\mathrm{E}$ vaccine that was licensed (HEV 239, Hecolin ${ }^{\circledR}$ ) [43•]. The WHO concluded that further studies were needed for worldwide licensing, especially on immunogenicity and protection in pregnant women, and safety data regarding maternal and fetal outcomes.

Since then, several studies have been initiated to evaluate safety and efficacy in various risk groups, such as in HBsAgpositive individuals showing positive results [44], in elderly persons (> 65 years of age) (NCT02417597), and when coadministered with a hepatitis B vaccine (NCT02584543). Currently, two clinical trials evaluating HEV239 are ongoing: a phase 1 safety study involving 25 males and non-pregnant females aged 18-45 years situated within the USA (NCT03827395), and a large phase IV study in Bangladesh including $\sim 20,000$ females aged 16-39 years, evaluating the protection of pregnant women (NCT02759991), the latter being discussed in more detail below. All these recent and ongoing studies will provide additional data on several of the issues raised by the WHO and should aid this vaccine to eventually obtain a global licensure.

The most recent HEV vaccine candidate to enter clinical trials is p179 (Changchun Institute of Biological Products Co., Ltd., Changchun, China), based on 439-617 part of ORF2 of a genotype 4 strain expressed in E. coli [45]. In a phase I trial in 2017, Cao et al. demonstrated the p179 vaccine to be safe and effective in healthy adults aged $16-65$ years, with a similar seroconversion and geometric mean concentration as the control vaccine HEV239 [46]. Cao et al. reported in 2017 that a phase II study was ongoing [46], but no results have been published so far. 


\section{Immunity}

A universal HEV vaccine could protect against the four HEV genotypes that cause infection in humans, as they all derive from a single serotype [47]. This has been the basis for the approach to obtain a vaccine suitable for use in all of the affected areas worldwide so far. However, some studies indicate that genotype-specific vaccines respond differently to different genotypes [48, 49]. Therefore, vaccines should document their effect on the different HEV genotypes.

Natural infection with one HEV genotype elicits crossprotection against all genotypes of HEV, but the immunity seems to be incomplete and of varying duration [11, 50]. The duration of anti-HEV IgG seems to vary widely depending on age, population, and genotype [11]. The number of anti-HEV T cells starts to decline rapidly approximately 1 year following infection, but HEV-specific memory $\mathrm{T}$ cells have been detected many years after infection [51].

The persistence of protective anti-HEV IgG antibodies is estimated to last longer following vaccination than it does after natural infection, based on antibody titers from the phase III clinical trial of HEV239. After 3 doses of HEV239, efficacy reached $93 \%$, and it was predicted that $99 \%$ of the vaccine recipients would remain seropositive for over 30 years, as opposed to natural infection, where a $50 \%$ seronegative conversion rate would occur after 14.5 years [52•].

Data from a smaller subset of participants who were part of the rHEV phase II vaccine trial showed that the vaccine had an efficacy of $95 \%$ after three doses (at 0,1 , and 6 months). However, after 720 days, only $56 \%$ of the participants had detectable anti-rHEV IgG antibodies (defined as $20 \mathrm{WR}$ $\mathrm{U} / \mathrm{ml}$ ) [37]. The increased seroreversion rate could partially be due to use of a detection method with lower sensitivity [53]. However, HEV239 seemingly induces longer-lasting immunity than the rHEV vaccine and natural infection.

The development of cross-protective anti-HEV IgG antibodies after vaccination with vaccines developed from specific genotypes (HEV239 and p179 derived from genotypes 1 and 4 , respectively) has also been examined. Utilizing data from a small clinical trial where 60 participants were vaccinated at 0,1 , and 6 months with either HEV239 or p179, antibody responses to specific neutralizing epitopes were measured 1 month after the last vaccination to determine whether genotype-specific epitopes exist. HEV239 induced slightly stronger responses against genotype 1 and 2 antigens than genotype 3 and 4 , while p179 induced slightly stronger responses against genotype 3 and 4 antigens than genotype 1 and 2 [49]. These differences may not, however, have clinical significance as HEV239 has already been shown to induce cross-protective responses against genotype 4 in the largescale trial of HEV239 [52•, 54].

\section{Vaccination to Protect Pregnant Women}

Pregnant women are one of the groups expected to benefit considerably from HEV vaccination due to their high morbidity and mortality from the disease. As a principle, no vaccine or other drug should be given to a pregnant woman unless the benefit is clearly greater than the potential risk of using drugs off-label. Since some infectious diseases are significant causes of maternal and neonatal morbidity and mortality, immunization of pregnant women is recommended in certain circumstances when shown safe, in order to protect the mother and her fetus or infant. For those newer vaccines, theoretical safety concerns may result in vaccination being withheld from pregnant women in particular [55]. HEV vaccine is, however, not yet evaluated for use in pregnant women. Currently there is one phase IV trial underway in Bangladesh to evaluate the protection of pregnant women who were immunized before pregnancy with the HEV239 vaccine (NCT02759991). In this study, the vaccine is administered to non-pregnant women of childbearing age who are followed up for a 2-year period to monitor for symptoms and outcome of HEV infection during pregnancy. The study aims to provide important data on effectiveness during pregnancy, but it will not address the question regarding safety of the vaccine when given to pregnant women. At present, no clinical trials are ongoing that specifically evaluate hepatitis $\mathrm{E}$ vaccination in pregnant women. Nonetheless, during the phase III trial of HEV239 in China [54], a few women were inadvertently vaccinated during pregnancy ( 37 women in the HEV 239 vaccine group and 31 women in the control group) [56*•], and similar rates of adverse events were observed in the pregnant women as the matched non-pregnant women. Data from the newborns (weights, body lengths, and gestational ages) were also comparable, which suggests that the HEV 239 vaccine is well-tolerated in pregnant women. Such safety data may also arise from the ongoing phase IV study in Bangladesh.

\section{Conclusions}

Hepatitis E virus poses a substantial risk for morbidity and mortality for pregnant women and their infants in many lowincome countries. The reason for this increased risk is uncertain, but alteration of the immune response from both virus and pregnancy is likely an important factor [9]. A vaccine against HEV which could be administered during pregnancy is therefore highly warranted, particularly in endemic regions or during large disease outbreak settings. The HEV239 vaccine is closest to global licensing, but there are limited data on 
maternal and fetal outcomes following the use of the vaccine during pregnancy, and it is therefore not yet recommended for pregnant women. However, the limited existing data are promising with regard to safety during pregnancy, and more data are likely to come when pregnant women are inadvertently vaccinated at early stages of pregnancy in ongoing or future trials, or even during regular use of HEV239 in China. Effectiveness data of HEV239-induced immunity in pregnant women are also lacking and should become available through the ongoing phase IV trial in Bangladesh.

Many argue that the benefits of HEV vaccination outweigh the risk of HEV disease among pregnant women and their fetus/infants, due to the high rates of death in this population. Outbreak reports call for vaccination of pregnant women in certain high-risk settings, stating that this could dramatically reduce number of deaths $[57,58]$. This is supported by the recent modeling study by Cooper et al. [59.•] that demonstrates the considerable benefit that may be achieved when including pregnant women in preventive vaccination regimes in outbreak settings. Furthermore, immunization of the mother is expected to result in passive protection of the infant by transplacental transmission of specific HEV IgG antibodies. The WHO recognizes that it might be necessary to use the vaccine in outbreak settings in high-risk groups such as pregnant women, even though they do not yet recommend it for routine programs [1]. In such settings, there is a need for an accelerated vaccination schedule in order to control HEV, and three doses at 0,7 , and 21 days have been tested with promising results [60•]. However, a two-dose regime should also be investigated with regard to controlling outbreaks.

Although the vaccine is not yet recommended for routine use during pregnancy, in outbreak settings it should be offered to protect pregnant women and their fetuses against the potential detrimental effects of HEV infection. This should be done in the context of a clinical trial to secure good quality data. As soon as sufficient efficacy and safety data are available, a prequalification by WHO should encourage implementation of the vaccine in endemic areas as a preventative measure for use in the general population or in high-risk groups.

\section{Compliance with Ethical Standards}

Conflict of Interest Cathinka Halle Julin and Joakim Øverbø, received a grant from The Norwegian Research Council and were employed on the HEV vaccine project.

Jennifer L. Dembinski, Kristian Hjortaas, Kathrine Stene-Johansen, Susanne Dudman, and Synne Sandbu declare that they have no conflict of interest.

Human and Animal Rights and Informed Consent This article does not contain any studies with human or animal subjects performed by any of the authors.

\section{References}

Papers of particular interest, published recently, have been highlighted as:

- Of importance

- Of major importance

1. WHO. Hepatitis E Fact Sheet [internet]. WHO. 08.07.2019. Available from: https://www.who.int/news-room/fact-sheets/ detail/hepatitis-e. Accessed 16.07.2019.

2. Balayan MS, Andjaparidze AG, Savinskaya SS, Ketiladze ES, Braginsky DM, Savinov AP, et al. Evidence for a virus in non-A, non-B hepatitis transmitted via the fecal-oral route. Intervirology. 1983;20(1):23-31. https://doi.org/10.1159/000149370.

3. Smith DB, Simmonds P. Classification and genomic diversity of enterically transmitted hepatitis viruses. Cold Spring Harb Perspect Med. 2018;8(9). doi:https://doi.org/10.1101/cshperspect.a031880.

4. Aggarwal R, Goel A. Natural history, clinical manifestations, and pathogenesis of hepatitis E virus genotype 1 and 2 infections. Cold Spring Harb Perspect Med. 2018. https://doi.org/10.1101/ cshperspect.a032136.

5. Perez-Gracia MT, Suay-Garcia B, Mateos-Lindemann ML. Hepatitis E and pregnancy: current state. Rev Med Virol. 2017. https://doi.org/10.1002/rmv.1929.

6. Berglov A, Hallager S, Weis N. Hepatitis E during pregnancy: maternal and fetal case-fatality rates and adverse outcomes - a systematic review. J Viral Hepat. 2019. https://doi.org/10.1111/jvh. 13129 Systematically reviewed the latest knowledge on hepatitis $\mathbf{E}$ during pregnancy with regard to case-fatality rates and adverse outcomes.

7. Lhomme S, Marion O, Abravanel F, Chapuy-Regaud S, Kamar N, Izopet J. Hepatitis E pathogenesis. Viruses. 2016;8(8). doi:https:// doi.org/10.3390/v8080212. Available from: https://www.ncbi.nlm. nih.gov/pmc/articles/PMC4997574/ Accessed 6 October 2019.

8. Walker CM. Adaptive immune responses in hepatitis A virus and hepatitis E virus infections. Cold Spring Harb Perspect Med. 2018. doi:https://doi.org/10.1101/cshperspect.a033472. Available from: https://www.ncbi.nlm.nih.gov/pmc/articles/PMC6531370/ Accessed 8 October 2019.

9. Perez-Gracia MT, Suay B, Mateos-Lindemann ML. Hepatitis E: an emerging disease. Infect Genet Evol. 2014;22:40-59. https://doi. org/10.1016/j.meegid.2014.01.002.

10. Tian Y, Huang W, Yang J, Wen Z, Geng Y, Zhao C, et al. Systematic identification of hepatitis E virus ORF2 interactome reveals that TMEM134 engages in ORF2-mediated NF-kappaB pathway. Virus Res. 2017;228:102-8. https://doi.org/10.1016/j.virusres. 2016.11.027.

11. Krain LJ, Nelson KE, Labrique AB. Host immune status and response to hepatitis e virus infection. Clin Microbiol Rev. 2014;27(1):139-65. https://doi.org/10.1128/cmr.00062-13 Available from: https://www.ncbi.nlm.nih.gov/pmc/articles/ PMC3910912/ Accessed 7 October 2019.

12. Huang S, Zhang X, Jiang H, Yan Q, Ai X, Wang Y, et al. Profile of acute infectious markers in sporadic hepatitis E. PLoS One. 2010;5(10):e13560. https://doi.org/10.1371/journal.pone.0013560 Available from: https://www.ncbi.nlm.nih.gov/pmc/articles/ PMC2958841/ Accessed 6 October 2019.

13. Zhang JZ, Im SW, Lau SH, Chau TN, Lai ST, Ng SP, et al. Occurrence of hepatitis E virus IgM, low avidity IgG serum antibodies, and viremia in sporadic cases of non-A, -B, and -C acute hepatitis. J Med Virol. 2002;66(1):40-8.

14. La Rocca C, Carbone F, Longobardi S, Matarese G. The immunology of pregnancy: regulatory $\mathrm{T}$ cells control maternal immune 
tolerance toward the fetus. Immunol Lett. 2014;162(1 Pt A):41-8. https://doi.org/10.1016/j.imlet.2014.06.013.

15. McCracken SA, Gallery E, Morris JM. Pregnancy-specific downregulation of NF-kappa B expression in T cells in humans is essential for the maintenance of the cytokine profile required for pregnancy success. J Immunol. 2004;172(7):4583-91. https://doi.org/ 10.4049/jimmunol.172.7.4583.

16. Yang C, Yu W, Bi Y, Long F, Li Y, Wei D, et al. Increased oestradiol in hepatitis $\mathrm{E}$ virus-infected pregnant women promotes viral replication. J Viral Hepat. 2018;25(6):742-51. https://doi.org/10.1111/ jvh. 12865 .

17. Singh S, Daga MK, Kumar A, Husain SA, Kar P. Role of oestrogen and its receptors in HEV-associated feto-maternal outcomes. Liver Int. 2019;39(4):633-9. https://doi.org/10.1111/liv.13928.

18. Yin X, Ying D, Lhomme S, Tang Z, Walker CM, Xia N, et al. Origin, antigenicity, and function of a secreted form of ORF2 in hepatitis E virus infection. Proc Natl Acad Sci U S A. 2018;115(18):4773-8. https://doi.org/10.1073/pnas.1721345115 Available from: https://www.ncbi.nlm.nih.gov/pmc/articles/ PMC5939091/ Accessed 6 October 2019.

19. Gouilly J, Chen Q, Siewiera J, Cartron G, Levy C, Dubois M et al. Genotype specific pathogenicity of hepatitis $\mathrm{E}$ virus at the human maternal-fetal interface. Nat Commun. 2018;9(1):4748. doi:https:// doi.org/10.1038/s41467-018-07200-2. Available from: https:// www.ncbi.nlm.nih.gov/pmc/articles/PMC6232144/ Accessed 7 October 2019. Demonstrated a mechanism that could explain the severity of $\mathrm{HEV}-1$ infection during pregnancy as compared with HEV-3 infection.

20. Knegendorf L, Drave SA, Dao Thi VL, Debing Y, Brown RJP, Vondran FWR, et al. Hepatitis E virus replication and interferon responses in human placental cells. Hepatol Commun. 2018;2(2): 173-87. https://doi.org/10.1002/hep4.1138 Available from: https:// www.ncbi.nlm.nih.gov/pmc/articles/PMC5796324/ Accessed 6 October 2019

21. Nair VP, Anang S, Subramani C, Madhvi A, Bakshi K, Srivastava A, et al. Endoplasmic reticulum stress induced synthesis of a novel viral factor mediates efficient replication of genotype-1 hepatitis $\mathrm{E}$ virus. PLoS Pathog. 2016;12(4):e1005521. https://doi.org/10.1371/ journal.ppat.1005521 Available from: https://www.ncbi.nlm.nih. gov/pubmed/27035822 Accessed 6 October 2019.

22. Kumar A, Sharma S, Kar P, Agarwal S, Ramji S, Husain SA, et al. Impact of maternal nutrition in hepatitis $\mathrm{E}$ infection in pregnancy. Arch Gynecol Obstet. 2017;296(5):885-95. https://doi.org/10. 1007/s00404-017-4501-y.

23. Bhatnagar G, Sharma S, Kumar A, Prasad S, Agarwal S, Kar P. Reduced glutathione in hepatitis $\mathrm{E}$ infection and pregnancy outcome. J Obstet Gynaecol Res. 2016;42(7):789-95. https://doi.org/ 10.1111/jog.12986.

24. Kamar N, Izopet J, Pavio N, Aggarwal R, Labrique A, Wedemeyer $\mathrm{H}$, et al. Hepatitis E virus infection. Nat Rev Dis Primers. 2017;3: 17086. https://doi.org/10.1038/nrdp.2017.86.

25. Webb GW, Dalton HR. Hepatitis E: an underestimated emerging threat. Ther Adv Infect Dis. 2019;6:2049936119837162. https:// doi.org/10.1177/2049936119837162 Available from: https://www. ncbi.nlm.nih.gov/pmc/articles/PMC6448100/ Accessed 5 October 2019.

26. Changede P, Chavan N, Raj N, Gupta P. An observational study to evaluate the maternal and foetal outcomes in pregnancies complicated with jaundice. J Obstet Gynaecol India. 2019;69(1):31-6. https://doi.org/10.1007/s13224-018-1105-9.

27. Li M, Bu Q, Gong W, Li H, Wang L, Li S, et al. Hepatitis E virus infection and its associated adverse feto-maternal outcomes among pregnant women in Qinhuangdao, China. J Matern Fetal Neonatal Med. 2019:1-5. https://doi.org/10.1080/14767058.2019.1582630.

28. Kumar RM, Uduman S, Rana S, Kochiyil JK, Usmani A, Thomas L. Sero-prevalence and mother-to-infant transmission of hepatitis E virus among pregnant women in the United Arab Emirates. Eur J Obstet Gynecol Reprod Biol. 2001;100(1):9-15. https://doi.org/10. 1016/s0301-2115(01)00448-1.

29. Krain LJ, Atwell JE, Nelson KE, Labrique AB. Fetal and neonatal health consequences of vertically transmitted hepatitis $\mathrm{E}$ virus infection. Am J Trop Med Hyg. 2014;90(2):365-70. https://doi.org/ 10.4269/ajtmh.13-0265 Available from: https://www.ncbi.nlm.nih. gov/pmc/articles/PMC3919250/ Accessed 8 October 2019.

30. Bertuzzo VR, Ravaioli M, Morelli MC, Calderaro A, Viale P, Pinna AD. Pregnant woman saved with liver transplantation from acute liver failure due to hepatitis E virus. Transpl Int. 2014;27(9):e87-9. https://doi.org/10.1111/tri.12305 Available from: https:// onlinelibrary.wiley.com/doi/full/10.1111/tri.12305 Accessed 7 October 2019.

31. Amanya G, Kizito S, Nabukenya I, Kalyango J, Atuheire C, Nansumba H, et al. Risk factors, person, place and time characteristics associated with hepatitis E virus outbreak in Napak District, Uganda. BMC infectious diseases. 2017;17(1):451. https://doi.org/ 10.1186/s12879-017-2542-2 Available from: https://www.ncbi. nlm.nih.gov/pmc/articles/PMC5485539/ Accessed 5 October 2019.

32. Okamoto H. Culture systems for hepatitis E virus. J Gastroenterol. 2013;48(2):147-58. https://doi.org/10.1007/s00535-012-0682-0.

33. Cao Y, Bing Z, Guan S, Zhang Z, Wang X. Development of new hepatitis E vaccines. Hum Vaccin Immunother. 2018;14(9):2254 62. https://doi.org/10.1080/21645515.2018.1469591 Available from: https://www.ncbi.nlm.nih.gov/pmc/articles/PMC6183316/ Accessed 6 October 2019.

34. Xing L, Kato K, Li T, Takeda N, Miyamura T, Hammar L, et al. Recombinant hepatitis E capsid protein self-assembles into a dualdomain $\mathrm{T}=1$ particle presenting native virus epitopes. Virology. 1999;265(1):35-45. https://doi.org/10.1006/viro.1999.0005.

35. Tsarev SA, Tsareva TS, Emerson SU, Govindarajan S, Shapiro M, Gerin JL, et al. Recombinant vaccine against hepatitis E: dose response and protection against heterologous challenge. Vaccine. 1997;15(17-18):1834-8.

36. Safary A. Perspectives of vaccination against hepatitis E. Intervirology. 2001;44(2-3):162-6. https://doi.org/10.1159/ 000050043.

37. Shrestha MP, Scott RM, Joshi DM, Mammen MP Jr, Thapa GB, Thapa N, et al. Safety and efficacy of a recombinant hepatitis E vaccine. N Engl J Med. 2007;356(9):895-903. https://doi.org/10. 1056/NEJMoa061847.

38. Park SB. Hepatitis E vaccine debuts. Nature. 2012;491(7422):21-2. https://doi.org/10.1038/491021a.

39. Li SW, Zhang J, Li YM, Ou SH, Huang GY, He ZQ, et al. A bacterially expressed particulate hepatitis $\mathrm{E}$ vaccine: antigenicity, immunogenicity and protectivity on primates. Vaccine. 2005;23(22):2893-901. https://doi.org/10.1016/j.vaccine.2004.11. 064.

40. Zhang J, Liu CB, Li RC, Li YM, Zheng YJ, Li YP, et al. Randomized-controlled phase II clinical trial of a bacterially expressed recombinant hepatitis E vaccine. Vaccine. 2009;27(12): 1869-74. https://doi.org/10.1016/j.vaccine.2008.12.061.

41. Zhang X, Wei M, Pan H, Lin Z, Wang K, Weng Z, et al. Robust manufacturing and comprehensive characterization of recombinant hepatitis E virus-like particles in Hecolin (®). Vaccine. 2014;32(32):4039-50. https://doi.org/10.1016/j.vaccine.2014.05. 064.

42. Zhang X, Wei M, Sun G, Wang X, Li M, Lin Z, et al. Real-time stability of a hepatitis $\mathrm{E}$ vaccine $(\operatorname{Hecolin}(\mathrm{R}))$ demonstrated with potency assays and multifaceted physicochemical methods. Vaccine. 2016;34(48):5871-7. https://doi.org/10.1016/j.vaccine. 2016.10.045.

43. Hepatitis E vaccine: WHO position paper, May 2015 Recommendations. Vaccine. 2016;34(3):304-5. doi:https://doi. 
org/10.1016/j.vaccine.2015.07.056. Summarized the essential background information on HEV and relevant vaccines, and stated the WHO position concerning their use in a global context.

44. Wu T, Huang SJ, Zhu FC, Zhang XF, Ai X, Yan Q, et al. Immunogenicity and safety of hepatitis $\mathrm{E}$ vaccine in healthy hepatitis B surface antigen positive adults. Hum Vaccin Immunother. 2013;9(11):2474-9. https://doi.org/10.4161/hv.25814.

45. Meng J, Dai X, Chang JC, Lopareva E, Pillot J, Fields HA, et al. Identification and characterization of the neutralization epitope(s) of the hepatitis E virus. Virology. 2001;288(2):203-11. https://doi.org/ 10.1006/viro.2001.1093.

46. Cao YF, Tao H, Hu YM, Shi CB, Wu X, Liang Q, et al. A phase 1 randomized open-label clinical study to evaluate the safety and tolerability of a novel recombinant hepatitis $\mathrm{E}$ vaccine. Vaccine. 2017;35(37):5073-80. https://doi.org/10.1016/j.vaccine.2017.05. 072.

47. Zhang J, Zhao Q, Xia N. Prophylactic hepatitis E vaccine. Adv Exp Med Biol. 2016;948:223-46. https://doi.org/10.1007/978-94-0240942-0 13.

48. Nan Y, Wu C, Zhao Q, Sun Y, Zhang YJ, Zhou EM. Vaccine development against zoonotic hepatitis E virus: Open questions and remaining challenges. Front Microbiol. 2018;9:266. https:// doi.org/10.3389/fmicb.2018.00266.

49. Wen J, Behloul N, Dai X, Dong C, Liang J, Zhang M, et al. Immunogenicity difference between two hepatitis $\mathrm{E}$ vaccines derived from genotype 1 and 4. Antivir Res. 2016;128:36-42. https:// doi.org/10.1016/j.antiviral.2016.02.002.

50. Kmush BL, Yu H, Huang S, Zhang X, Wu T, Nelson KE, et al. Long-term antibody persistence after hepatitis $\mathrm{E}$ virus infection and vaccination in Dongtai, China. Open Forum Infect Dis. 2019;6(4): ofz144. https://doi.org/10.1093/ofid/ofz144 Available from: https:// www.ncbi.nlm.nih.gov/pmc/articles/PMC6475590/ Accessed 8 October 2019

51. Hakim MS, Ikram A, Zhou J, Wang W, Peppelenbosch MP, Pan Q. Immunity against hepatitis $\mathrm{E}$ virus infection: implications for therapy and vaccine development. Rev Med Virol. 2018;28(2). doi: https://doi.org/10.1002/rmv.1964.

52. Su YY, Huang SJ, Guo M, Zhao J, Yu H, He WG et al. Persistence of antibodies acquired by natural hepatitis $\mathrm{E}$ virus infection and effects of vaccination. Clin Microbiol Infect. 2017;23(5):336.e1.e4. doi:https://doi.org/10.1016/j.cmi.2016.10.029. Available from: https://www.clinicalmicrobiologyandinfection.com/article/ S1198-743X(16)30550-X/fulltext Accessed 4 October 2019. Demonstrated the persistence of antibodies acquired by natural $\mathrm{HEV}$ infection versus by vaccination.

53. Innis BL, Seriwatana J, Robinson RA, Shrestha MP, Yarbough PO, Longer CF, et al. Quantitation of immunoglobulin to hepatitis $\mathrm{E}$ virus by enzyme immunoassay. Clin Diagn Lab Immunol. 2002;9(3):639-48.

54. Zhu FC, Zhang J, Zhang XF, Zhou C, Wang ZZ, Huang SJ, et al. Efficacy and safety of a recombinant hepatitis $E$ vaccine in healthy adults: a large-scale, randomised, double-blind placebo-controlled, phase 3 trial. Lancet. 2010;376(9744):895-902. https://doi.org/10. 1016/s0140-6736(10)61030-6.

55. Keller-Stanislawski B, Englund JA, Kang G, Mangtani P, Neuzil K, Nohynek H, et al. Safety of immunization during pregnancy: a review of the evidence of selected inactivated and live attenuated vaccines. Vaccine. 2014;32(52):7057-64. https://doi.org/10.1016/j. vaccine.2014.09.052.

$56 . \bullet$ Wu T, Zhu FC, Huang SJ, Zhang XF, Wang ZZ, Zhang J, et al. Safety of the hepatitis $\mathrm{E}$ vaccine for pregnant women: a preliminary analysis. Hepatology. 2012;55(6):2038. https://doi.org/10.1002/ hep. 25522 The only study so far that have evaluated the safety of HEV vaccine when given to pregnant women.

57. Boccia D, Guthmann JP, Klovstad H, Hamid N, Tatay M, Ciglenecki I, et al. High mortality associated with an outbreak of hepatitis E among displaced persons in Darfur. Sudan Clin Infect Dis. 2006;42(12):1679-84. https://doi.org/10.1086/504322.

58. Teshale EH, Howard CM, Grytdal SP, Handzel TR, Barry V, Kamili $\mathrm{S}$, et al. Hepatitis E epidemic, Uganda. Emerg Infect Dis. 2010;16(1):126-9. https://doi.org/10.3201/eid1601.090764 Available from: https://www.ncbi.nlm.nih.gov/pmc/articles/ PMC2874362/ Accessed 7 October 2019.

59.• Cooper BS, White LJ, Siddiqui R. Reactive and pre-emptive vaccination strategies to control hepatitis $\mathrm{E}$ infection in emergency and refugee settings: a modelling study. PLoS Negl Trop Dis. 2018;12(9):e0006807. doi:https://doi.org/10.1371/journal.pntd. 0006807. Available from: https://www.ncbi.nlm.nih.gov/pmc/ articles/PMC6173446/ Accessed 8 October 2019. Modelled the effect of HEV vaccination on mortality in outbreak settings if pregnant women were also given vaccine through reactive and pre-emptive strategies.

60. Chen Z, Lin S, Duan J, Luo Y, Wang S, Gan Z, et al. Immunogenicity and safety of an accelerated hepatitis $E$ vaccination schedule in healthy adults: a randomized, controlled, openlabel, phase IV trial. Clin Microbiol Infect. 2019. https://doi.org/ 10.1016/j.cmi.2019.01.015 Showed immunogenicity and safety of an accelerated schedule of HEV239, providing useful data for outbreak settings.

Publisher's Note Springer Nature remains neutral with regard to jurisdictional claims in published maps and institutional affiliations. 